P-ISSN: 2774-4574; E-ISSN: 2774-4582 TRILOGI, 1(1), Mei-Agustus 2020 (13-28) @2020 Lembaga Penerbitan, Penelitian, dan Pengabdian kepada Masyarakat (LP3M) Universitas Nurul Jadid Paiton Probolinggo DOI: https://doi.org/

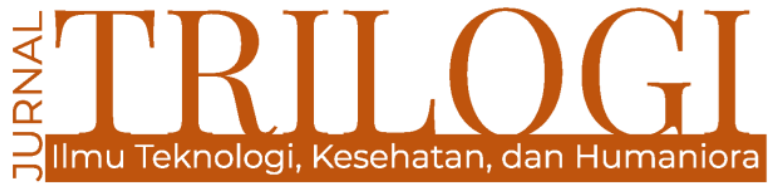

\title{
POPULISME RELIGIUS: \\ Promosi Image-Branding Majelis Shalawat dalam Industri Dakwah Kontemporer ${ }^{*}$
}

\author{
Anisah Nur Laili \\ UIN Sunan Ampel Surabaya, Indonesia \\ anisah.nurlaili@gmail.com
}

\begin{abstract}
This study aims to show majalis shalawat as a new religious market in contemporary Indonesia. Focusing on Syubbanul Muslimin and related to other majelis shalawat groups, this study analyzed kiai, gus, or habaib's approaches in marketing and expanding the Islamic da'wah industry in urban and rural areas. The results showed that while most religious preachers use public speaking skills in religious markets, a leader of the Syubbanul Muslim and other majelis shalawat leaders are utilizing performance in improving their religious and market authority. Through this performance, they are actually deploying marketing strategies of promotion and image-branding to increase the number of followers.
\end{abstract}

Keywords: Syubbanul Muslimin; promotion; image-branding; da'wah industry

\begin{abstract}
Abstrak
Studi ini ingin menunjukkan majalis shalawat sebagai pasar keagamaan baru di Indonesia kontemporer. Berfokus pada Syubbanul Muslimin dan berkaitan dengan kelompok majelis shalawat lainnya, studi ini menganalisis pendekatan yang digunakan kiai, gus, atau habaib dalam tradisi pemasaran dalam memperluas industri dakwah Islam di daerah perkotaan dan pedesaan. Hasil penelitian menunjukkan bahwa sementara muncul sebagian besar penceramah menggunakan keterampilan berbicara di depan umum di pasar keagamaan, pemimpin Majelis Syubbanul Muslimin dan para pemimpin majelis shalawat lainnya memanfaatkan performa dalam meningkatkan otoritas agama dan pasar mereka. Melalui performa ini, mereka sebenarnya sedang menjalankan strategi promosi dan pencitraan untuk meningkatkan jumlah anggotanya.
\end{abstract}

Katakunci: Syubbanul Muslimin; promosi; image-branding; industri dakwah

* Artikel ini sebagian merupakan intisari atas beberapa bagian dari riset penulis berjudul "Partisipasi Pemuda dalam Majelis Ta'lim dan Shalawat Syubbanul Muslimin dan Outcome terhadap Psikologi Pemuda di Paiton Probolinggo", Tesis, UIN Sunan Ampel Surabaya, 2017. 


\section{Pendahuluan}

Studi ini ingin menunjukkan majalis shalawat sebagai pasar keagamaan baru di Indonesia kontemporer. Berfokus pada Syubbanul Muslimin dan berkaitan dengan kelompok majelis shalawat lainnya, studi ini menganalisis pendekatan yang digunakan kiai, gus, atau habaib dalam tradisi pemasaran dalam memperluas industri dakwah Islam di daerah perkotaan dan pedesaan. Sementara tren yang muncul menunjukkan bahwa sebagian besar penceramah menggunakan keterampilan berbicara di depan umum di pasar keagamaan, Gus Hafidz dan para pemimpin majelis shalawat lainnya memanfaatkan performa dalam meningkatkan otoritas agama dan pasar mereka. Penampilan mereka mengekspresikan kombinasi tradisionalisme, kesucian, kewalisongoan, dan kearaban. Menggunakan internet dan budaya populer, mereka mempromosikan diri sebagai orang suci yang hidup dengan memanfaatkan status silsilah Walisongo atau Sayyid mereka dan menekankan peran leluhur mereka dalam Islamisasi. Dalam hal ini, penggunaan gelar kiai, gus, atau habib, khas, dan nama keluarga sangat penting dalam mengekspresikan status mereka dan etnis Arab. Dengan menggunakan majelis sebagai sarana terhadap kecintaan Nabi, mereka telah menawarkan model baru kesalehan tradisionalis di kalangan pemuda Muslim. Branding semacam itu menyiratkan bahwa dakwah mereka lebih dekat dengan misi Nabi, dan karena itu lebih otentik dan berwibawa daripada kelompok dakwah lainnya.

Kasus Majelis Shalawat Syubbanul Muslimin menunjukkan bahwa tradisi dapat dimediasi dan dipasarkan di daerah perkotaan dan pedesaan. Studi ini melengkapi studi sebelumnya yang sebagian besar berfokus pada ekspresi dakwah modern dalam pengaturan perkotaan. Dakwah perkotaan biasanya disesuaikan untuk menarik konstituensi Muslim yang luas. Selain itu, ia cenderung mengakomodasi selera modern kelas menengah Muslim dan meminimalkan penampilan dan ritual tradisionalis. Akan tetapi, majelis shalawat berbeda dan menghadapi pola umum ini. Alih-alih akomodatif, kegiatan shalawat mereka ditargetkan pada kelompok Muslim tertentu. Kondisi ini mempromosikan Islam tradisionalis (aswaja) yang hanya menarik bagi komunitas Muslim tradisionalis yang secara budaya terkait dengan Nadhlatul
Ulama. Majelis shalawat telah mengidentifikasi kesenjangan pasar dan pindah ke dalamnya, mempromosikan praktik renungan yang memenuhi kebutuhan dan aspirasi tradisionalis perkotaan. Dengan menggunakan media baru dan pasar keagamaan, pemimpin majelis shalawat, kiai, gus, dan habaib tidak hanya berhasil mempopulerkan tradisi, tetapi mereka juga mendapatkan peningkatan kedudukan agama, ketenaran, dan imbalan keuangan dari umat.

Dalam risetnya yang berjudul "Ordering What is Right, Forbidding What is Wrong: Two Faces of Hadhrami Dakwah in Contemporary Indonesia", Mark Woodward dkk. (2012: 106) menyatakan bahwa shalawatan merupakan bagian dari tradisi tarekat (sufi order) yang berkembang di Timur Tengah, terutama Hadramaut (sekarang Yaman, red.). Di Indonesia, munculnya habaib (habib-habib) merupakan kontestasi dominasi sayyid Hadrami di Indonesia, khususnya di perkotaan sejak tahun 1980an dengan menggunakan modalmodal religius (religious capital). Cara tersebut terbukti sukses menarik minat para elit dan Muslim akar rumput diasporik di Asia Tenggara, termasuk di Indonesia. Di sini muncullah pergelaran habaib, yang terkenal adalah Habib Syech, sebagai bentuk dakwah secara damai atau dalam Islam disebut amr al-ma'ruf dengan tiga dasar kesalehan Muslim (traditional Muslim piety), yakni shalawat, barokah, dan doa.

Sementara itu, Akh Muzakki dalam artikelnya "Islam as A Symbolic Commodity: Transmitting and Consuming Islam through Public Sermons in Indonesia" (dalam Kitiarsa, 2008: 205) juga memaparkan berbagai bentuk konsumsi dan produksi Islam di kalangan umat Muslim kontemporer. Salah satunya direpresentasikan dalam khutbah Jum'at di berbagai kampus, utamanya di kalangan dosen UIN Sunan Ampel Surabaya. Muzakki sampai pada kesimpulan bahwa Islam telah menjadi sejenis komoditas simbolik baik secara intelektual dan material. Ia mencontohkan, antara lain, khotbah Jum'at di masjid-masjid kampus keagamaan Islam yang kini telah menjadi sejenis media tidak hanya untuk mentransmisi Islam kepada publik, tetapi juga mengakumulasikan kesejahteraan dan meningkatkan status sosial mereka.

Selain dalam seremoni-seremoni publik, transimisi Islam melalui musik-musik religius juga bermunculan, sebagaimana yang digarap 
dalam studi Bart Barendregt dan Wim van Zanten, "Popular Music in Indonesia since 1998, in Particular Fusion, Indie, and Islamic Music on VideoCompact Discs and the Internet" (2002). Studi ini memperlihatkan kecenderung musikmusik Islami sebagai popular music melalui produksi indie. Lagu rohani kemudian menjadi label pada setiap musik religius dengan tematema kenabian, ketuhanan, maupun lagu berbahasa Arab. Musik religius mengalami pertumbuhan pesat di Indonesia pascareformasi, menurut Barendregt, terjadi sebagai upaya negosiasi identitas berbasis komunitas yang memainkan perannya dalam dialog di tingkat lokal, nasional, dan global (hlm. 1).

Tumbuhnya industri musik religius ini tidak hanya terjadi di Indonesia. Charles Hirschkind dalam tulisannya, "Cassette Ethics: Public Piety and Popular Media in Egypt" (2005) memperlihatkan di Mesir telah terjadi hal serupa. Munculnya media popular ini menurutnya menandaskan adanya kemunculan praktik "kontestasi agama" (contestatory religion). Kontestasi ini terjadi ketika teknologi perekaman masuk ke Mesir tahun 1970an, komunitas Muslim, pendakwah, maupun qori' melakukan perekaman khutbah, hadits, dan sebagainya ke dalam sebuah media kaset. Hadirnya kaset khutbah (sermon cassette) telah mengubah praktik beragama orang Mesir yang juga disituasikan oleh konteks politik dan demokratisasi. Di sisi lain, kaset dapat menjadi arena komodifikasi agama baru bagi para pedagang spiritual.

Studi yang dilakukan oleh Fairuz, "Maulid and Shalawat in Popular Culture Perspective: Study of Jamaah Ahbabul Musthofa Yogyakarta" (2013) juga memperlihatkan adanya praktik komodifikasi agama dalam Majelis Ahbabul Musthafa. Menurutnya, tradisi shalawat telah mengalami komodifikasi dan massifikasi yang kemudian membentuk fanatisme pada pengikutnya yang dikenal dengan "Syechermania" (hlm. 69). Komodifikasi ini terjadi melalui publikasi beberapa album dan beberapa aksesoris Ahbabul Musthofa yang pada gilirannya telah mendatangkan nilai ekonomi dan penguatan identitas bagi jamaahnya. Musik, kaset, dan produk lainnya diproduksi dan dikonsumsi melalui industri rekaman, musik mengalami duplikasi dan disebarkan ke berbagai lapisan masyarakat melampaui batas ruang dan waktu.
Yang relevan juga dengan riset Fairuz di atas adalah studi Nur Rosyid berjudul "Pembentukan Hasrat Bershalawat Bersama Habib dalam Konteks Kapitalisme Lanjut di Indonesia" (2008). Penelitian ini berhasil menunjukkan bahwa kegiatan shalawat bersama yang dilakukan oleh Ahbabul Mustofa di Solo menjadi semacam arena pembentukan hasrat religiustas-estetis yang terangkut dalam ide mengenai kedamaian. Acara shalawat bersama ternyata tidak hanya menjadi ritus mengungkapkan kecintaan kepada nabi, tetapi juga ritus institusionalisasi genealogi sayyid dan eksklusivitasnya. Melalui berbagai upaya penginderaan secara terus menerus dan hiperestetis, shalawat bersama tersebut telah menjadi sejenis waralaba sendiri yang mampu mengarahkan kecenderungan hasrat para pesertanya.

\section{Metode}

Karena yang diteliti oleh studi ini adalah sistem kebudayaan pada komunitas tertentu, maka etnografi dipilih sebagai metode penelitian. Pendekatan etnografis berfokus pada makna, proses, dan konteks sosio-kultural tertentu; biasanya menggunakan data emic dan ethic; didasarkan pada kajian lapangan; dan menerapkan proses interpretatif, reflektif, dan konstruktif secara berkelanjutan (Whitehead, 2004: 5). Di sini, penulis mengumpulkan data dengan melaksanakan observasi partisipan secara intensif kepada para peserta Majelis Syubbanul Muslimin sejak Juli-November 2017 di Probolinggo.

Data primer berasal dari hasil wawancara dengan para partisipan, perilaku dan aktivitasnya dalam kegiatan majelis Syubbanul Muslimin. Dokumentasi berupa foto dan teksteks shalawat juga menjadi bagian penting yang akan digali dalam studi ini. Partisipan dipilih dengan teknik purposive sampling, hanya mereka yang sesuai dengan kebutuhan subjektif peneliti terhadap tema yang dipilih (Lazuardi, 2009: 19).

Termasuk juga yang akan digali adalah bagaimana mereka menggunakan media sosial sebagai strategi marketingnya. Sementara itu, data yang berasal dari artikel jurnal, berita, atau buku-buku menjadi referensi sekunder untuk memperkaya data primer di atas.

Selain wawancara dan partisipasi, digunakan pula dokumentasi untuk meningkatkan kualitas data yang dikumpulkan. 
Dokumentasi berupa video, foto, atau teks dapat represents these as place-making encounters between researcher, participants, and the material/sensory environment (merepresentasikan perjumpaan praksis antara peneliti, partisipasi, dan lingkungan sensoriknya) (Dicks, 2013: 5). Dalam hal ini, foto dan video yang akan ditampilkan nantinya tidak semata-mata digunakan sebagai perekaman fenomena shalawat bersama, tetapi juga bentuk partisipasi yang melibatkan pengalaman penulis dalam acara shalawat Majelis Syubbanul Muslimin.

Karena pendekatan yang digunakan adalah etnografi inderawi, maka analisis datanya harus didasarkan pada pendekatan tersebut. Salah satu asumsi etnografi inderawi adalah koding makna-makna kultural. Menurut Classen (dalam Howes, 1991: 401), makna kultural itu direduksi dari data yang hanya memiliki "signifikansi kultural" (cultural significance). Dalam konteks penelitian ini, reduksi data yang memiliki signifikansi kultural itu dilakukan dengan mengkoding beragam jenis data berdasarkan tema dan tipologi yang telah disusun, yakni: komodifikasi shalawat dan waralaba religius. Rinciannya bisa berupa strategi marketing, sistem manajemen, reproduksi modal shalawat, rutinitas kegiatan, dan pengalaman sensorik atas kegiatan majelis Syubbanul Muslimin.

Setelah koding dilakukan, maka tahap selanjutnya adalah mendisplay data (Miles dan Huberman, 1984: 39). Di sini, data-data tersebut ditranskripsi, ditampilkan, dan disajikan dalam bentuk teks tertulis. Video kegiatan Syubbanul Muslimin ditranskripsi, hasil wawancara dengan peserta Syubbanul Muslimin juga ditampilkan, teks-teks shalawat atau barzanji juga disajikan, dan poster-poster offline serta online juga dimunculkan sejauh mereka berkaitan dengan dan berkontribusi terhadap proses komodifikasi shalawat yang terjadi dalam majelis tersebut.

Selanjutnya, seperti riset pada umumnya, dibutuhkan suatu verifikasi atas data melalui banyak tahapan, seperti triangulasi. Di sinilah penting mewawancarai bukan hanya peserta majelis Syubbanul Muslimin, melainkan juga para penonton yang tidak hadir tapi membaca poster-poster majelis tersebut. Triangulasi metodologis dilakukan dengan memastikan adanya koherensi antara data dokumen, wawancara, dan hasil observasi.
Yang jelas, verifikasi data tetaplah bersifat subjektif, karena ia melibatkan pengalaman dan penginderaan peneliti, yang secara teoretis lebih dikenal sebagai pendekatan intensionalitas fenomenologis (phenomenological intentionality) (Hardiman, 2007: 44). Penekannya adalah memberi perhatian penuh pada dunia sekeliling; bagaimana kemampuan peneliti dalam mempersepsi dan mengintensi diarahkan dan dibentuk untuk memverifikasi data penelitian.

\section{Diskusi dan Pembahasan \\ 3.1. Syubbanul Muslimin: Sebuah Profil Singkat}

Keberadaan Syubbanul Muslimin berawal dari problem sosial yang terjadi di lingkungan Desa Kalikajar, di antaranya peredaran minuman keras, mabuk-mabukan, narkoba, tawuran antar pelajar dan lain sebagainya. Semenjak terjadi permasalahan sosial yang kian mengkhawatirkan terhadap pemuda Kalikajar bahkan berujung tawuran antar desa dan antar kelompok pemuda telah menjadi hal yang lumrah karena terjadi hampir setiap minggunya.

Menimbang bahaya tersebut, muncullah keprihatinan dari KH. Hafidzul Hakiem Noer atau yang akrab dipanggil Gus Hafidz selaku penggagas majelis syubbanul muliminuntukmemperhatikan nasib remaja dan para pemuda di lingkungan sekitarnya. Secara perlahan, GusHafidz (panggilan akrabnya) meninjau dan mempelajari psikologis para pemuda di lingkungan sekitarnya. Perlahan tapi pasti Gus Hafidz meninjau dan mempelajari psikologis para pemuda milenial di lingkungannya (Haq, 2019).

Berdasarkan hasil pengkajian Gus Hafidz terhadap lingkungan sekitar, dia menemukan ide kreatif untuk mengakomodir para remaja dengan kegiatan positif yakni membuat kegiatan keagamaan berupa shalawatan. Awalnya para pemuda dikumpulkan dan diajak ngopi dengan harapan mengajak anak mudatersebut untuk shalawatan.

Kegiatan shalawatan ini dibentuk oleh Gus Hafidz secara bertahap dimana waktu itu hanya beranggotakan 40 pemuda sekitar Pondok Pesantren Nurul Qodim Desa Kalikajar, pada Hari Jum'at 25 November 2005. Majelis ini kemudian diberi nama Majelis Syubbanul Muslimin oleh $\mathrm{KH}$. Nuruddin Musyiri, yang 
memiliki arti Pemuda-Pemudi Islam (Haq, 2019).

Kegiatan shalawat ini pada mulanya berpindah-pindah dari rumah ke rumah para pemuda yang ikut majelis ini, sehingga secara perlahan masyarakat sekitar mulai mengenal Syubbanul Muslimin lebih dekat. Kegiatan shalawat tersebut kemudian menjadi rutinitas seminggu dua kali yakni setiap malam selasa dan sabtu, sehingga oleh Gus Hafidz bersama Majelis Syubbanul Musliminmulai dapat mempengaruhi pemuda- pemudi sekitar ke jalan yang lebih benar dengan sentuhan shalawatan secara berangsur (Haq, 2019).

Keberadaan Majelis Syubbanul Muslimin di tengah-tengah masyarakat khususnya Desa Kalikajar membuat perilaku remaja berubah ke arah yang lebih baik. Kegiatan sehari-hari mereka lebih berguna dengan mengikuti shalawatan bahkan telah banyak yang bergabung dengan tim di Syubbanul Muslimin seperti tim multimedia, tim koperasi, tim keamanan, tim sound sistem dan tim lainnya yang turut mendukung Majelis Syubbanul Muslimin membumikan shalawat.

Saat ini, Majelis Syubbanul Muslimin menjelma sebagai sebuah kelompok shalawat milenial dalam upaya mengajak orang untuk senantiasa cinta pada Allah dan Rasulullah dengan membaca shalawat sesuai misi yang dibuatnya. Majelis ini senantiasa istiqomah dalam upaya mengajak orang-orang bersamasama melantunkan shalawat, menjadikan shalawat sebagai tuntunan adalah hal prioritas yang selalu ditanamkan pada umat.

\section{a. Visi, Misi, dan Struktur Organisasi Majelis Syubbanul Muslimin}

Sebagaimana sebuah lembaga atau institusi religius pada umumnya, Majelis Syubbanul Muslimin juga dilengkapi dengan visi, misi, dan struktur organisasi di dalamnya.

Visi Majelis Syubbanul Muslimin: Menjadikan shalawat sebagai tuntunan bukan tontonan, sementara misinya adalah 1) Menanamkan cinta kepada Allah dan Rasulullah SAW; dan 2) Membumikan shalawat. Sebagaimana yang akan terlihat nanti, meskipun visi Syubbanul Muslimin adalah menjadikan shalawat sebagai tuntunan, bukan tontonan, ia menggunakan strategi 'tontonan', seperti promosi, branding, hingga marketing untuk membumikan shalawat kepada para jamaahnya.
Struktur Organisasi Majelis Syubbanul Muslimin tidaklah sesederhana yang dibayangkan. Karena basis 'pertunjukan' majelis ini adalah panggung dengan berbagai macam aksesoris di dalamnya, dibutuhkan suatu struktur organisasi yang kuat. Ada vokalis, ketua, sekretaris umum, tim multimedia, hingga tim patwal dan tim kesehatan.

Berikut ini adalah struktur organisasi Syubbanul Muslimin.

Vokalis Syubbanul Muslimin

1. Muhammad Ulul Azmi Azkandar Al-Abshor

2. Hafidul Ahkam

3. Muhammad Nurus Syaban

4. Irsyadul Ibad

Ketua: KH. Hafidzul Hakiem Noer

Sekretaris Umum: Muhammad Bahri

Bendahara Umum: H. Muhammad Mahfud

Koordinator Lapangan: SyakurTim Dekorasi:

Stamleo

Tim Panggung: Ridwan

Tim Penerangan: Aziz

Sound Sistem: H. Edi

Tim Multimedia: Babun Ni“am

Tim Hadrah: Mukhalis Majid

Tim Keamanan: Mad Tali

Tim Patwal: NoryoTim Montir: Ilham

Tim Kesehatan: Muhammad Huda

Tim Koperasi: Sukar

(Catatan: Ini merupakan struktur terbaru pada 2020, meskipun hasil wawancara yang telah dilakukan sejak tahun 2017 memperlihatkan bahwa telah ada perubahan struktur di dalamnya)

Tabel 1. Beberapa Sampel Deretan Lagu Majelis Syubbanul Muslimin

\begin{tabular}{llll} 
No & $\begin{array}{l}\text { Jadwal } \\
\text { Pementasan }\end{array}$ & Judul Lagu & Acara \\
\hline 1 & 07 Agustus & Menggapai & Gebyar Maulid \\
& 2017 & Cintanya & $\begin{array}{l}\text { Nabi } \\
\text { Muhammad } \\
\end{array}$ \\
& & SAW di \\
& & Pondok \\
& & Pesantren \\
& & & Asshidiqiyah \\
& & & Karawang \\
\hline & & & Peringatan \\
& & Hari Santri \\
& 22 Oktober & Aku rindu & Nasional di \\
& 2017 & & Kota \\
& & & Probolinggo \\
\hline & & & Hari Ulang \\
& & tahun ke-36 \\
\hline 3 & 16 Desember & Jaran Goyang & \\
& 2017 & versi &
\end{tabular}




\begin{tabular}{|c|c|c|c|}
\hline & & & $\begin{array}{l}\text { KH. Hafidzul } \\
\text { Hakiem Noer }\end{array}$ \\
\hline 4 & 01 April 2018 & Ya Syaikhona & $\begin{array}{l}\text { Tabligh Akbar } \\
\text { Peringatan } \\
\text { Isro" Mi“roj } \\
\text { Nabi } \\
\text { Muhammad } \\
\text { SAW di Kota } \\
\text { Tegal }\end{array}$ \\
\hline 5 & 09 Juli 2018 & $\begin{array}{l}\text { Air Mata } \\
\text { Kerinduan }\end{array}$ & $\begin{array}{l}\text { Halal Bihalal } \\
\text { Po“3NK } 69\end{array}$ \\
\hline 6 & $\begin{array}{l}15 \\
\text { September } \\
2018\end{array}$ & Ayah & $\begin{array}{l}\text { Tahun Baru } \\
\text { Islam di } \\
\text { Balikpapan }\end{array}$ \\
\hline 7 & $\begin{array}{l}06 \text { Oktober } \\
2018\end{array}$ & "Dilan" & $\begin{array}{l}\text { Deklarasi } \\
\text { Samawi di } \\
\text { Kota } \\
\text { Semarang }\end{array}$ \\
\hline 8 & $\begin{array}{l}22 \text { Oktober } \\
2018\end{array}$ & Sahabat Jabir & $\begin{array}{l}\text { Peringatan } \\
\text { Hari Santri } \\
\text { Nasional di } \\
\text { Pondok } \\
\text { Pesantren } \\
\text { Nurul Jadid } \\
\text { Kabupaten } \\
\text { Probolinggo } \\
\end{array}$ \\
\hline 9 & $\begin{array}{l}02 \text { November } \\
2018\end{array}$ & $\begin{array}{l}\text { Deen Assalam } \\
\text { Versi } \\
\text { Syubband }\end{array}$ & $\begin{array}{l}\text { Walimatul } \\
\text { Aqiqoh Adibah } \\
\text { Sajidah } \\
\text { Rahman }\end{array}$ \\
\hline 10 & $\begin{array}{l}13 \text { November } \\
2018\end{array}$ & $\begin{array}{l}\text { Selamat Ulang } \\
\text { Tahun } \\
\text { Majelisku }\end{array}$ & $\begin{array}{l}\text { Milad ke-12 } \\
\text { Syubbanul } \\
\text { Muslimin }\end{array}$ \\
\hline 11 & 03 Mei 2019 & $\begin{array}{l}\text { Sarjana } \\
\text { (Sarungan aja } \\
\text { kemana-mana }\end{array}$ & $\begin{array}{l}\text { HUT ke-10 } \\
\text { MAN } 4 \\
\text { Bojonegoro }\end{array}$ \\
\hline 12 & 11 Mei 2019 & Ramadhan & $\begin{array}{l}\text { Tasyakkuran } \\
\text { Khitan Moh. } \\
\text { Arya Taufiqul } \\
\text { Hakiki }\end{array}$ \\
\hline 13 & $\begin{array}{l}08 \text { November } \\
2019\end{array}$ & $\begin{array}{l}\text { Cinta dalam } \\
\text { istikhoroh }\end{array}$ & $\begin{array}{l}\text { Haul KH. } \\
\text { Sholikin } \\
\text { Hamzah dan } \\
\text { Jami“iyah } \\
\text { Mahabbatil } \\
\text { Rosul di } \\
\text { Kabupaten } \\
\text { Jombang }\end{array}$ \\
\hline 14 & $\begin{array}{l}09 \text { November } \\
2019\end{array}$ & $\begin{array}{l}\text { Kisah sang } \\
\text { rasul versi } \\
\text { Syubband }\end{array}$ & $\begin{array}{l}\text { Pondok } \\
\text { Pesantren Al- } \\
\text { Rosyid } \\
\text { Bojonegoro }\end{array}$ \\
\hline 15 & $\begin{array}{l}26 \text { Januari } \\
2020\end{array}$ & $\begin{array}{l}\text { Kami Santri } \\
\text { Bukan Artis }\end{array}$ & $\begin{array}{l}\text { Pelantikan PC } \\
\text { Ansor Kota } \\
\text { Tegal }\end{array}$ \\
\hline 16 & $\begin{array}{l}29 \text { Februari } \\
2020\end{array}$ & $\begin{array}{l}\text { Syubband } \\
\text { LoversNusanta } \\
\text { ra }\end{array}$ & $\begin{array}{l}\text { Maulid Nabi } \\
\text { Muhammad } \\
\text { SAW Pondok } \\
\text { Pesantren } \\
\text { Suniyah } \\
\text { Salafiyah Al- } \\
\text { Khairiyah } \\
\text { Kabupaten } \\
\text { Bekasi }\end{array}$ \\
\hline
\end{tabular}

Sebenarnya, masih banyak lagu lain yang dilantunkan oleh majelis ini di berbagai tempat di daerah-daerah di Indonesia. Namun, sampel di atas sudah memperlihatkan bahwa majelis ini memang mengikuti trend lagu milenial yang sasarannya sebenarnya adalah untuk mempersuasi pemuda-pemudi Islam, sebagaimana makna dari nama majelis ini.

\section{b. Makna Lambang Syubbanul Muslimin}

Uniknya, lambang Syubbanul Muslimin mengikuti lambang lembaga keagamaan Islam pada umumnya, yang terdiri dari kubah, lambang sabit dan bintang, lalu huruf Arab. Komposisi desain ini sebenarnya lumrah digunakan oleh banyak sekali lembaga keagamaan Islam. Tampaknya, Tim Kreatif Syubbanul Muslimin tidak mengambil risiko untuk menampilkan logo-logo yang relatif kontroversial dan bergaya milenial.

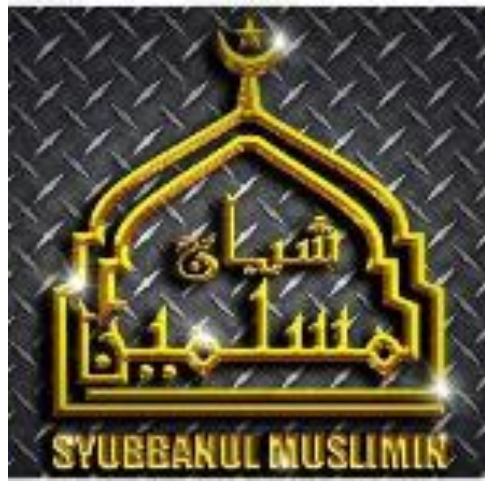

Gambar 1. Lambang Majelis Syubbanul Muslimin

1. Satu bintang di atas bermakna Allah

2. Bulan sabit bermakna Nabi Muhammad. Nabi adalah badrun atau rembulan.

3. Ditopang dan dijunjung tinggi tiang bermakna keduanya adalah ruh perjuangan kami.

4. Kubah di bawahnya berwarna hujau yaitu Qubbah al-Khadra'(kubah makam Nabi Muhammad SAW). Bermaknakita ingin menyebarkan nilai-nilai perjuangan Rasulullah SAW.

5. Di bawahnya ada tulisan Syubbanul Musliminditulis dengan lentur dan ada sedikit bunga pada huruf nun, menunjukkan dakwah kita lembut dengan merangkul dan bersaudara.

6. Warna kuning emas pada lambang bermakna arti kebahagiaan karena kita ingin mengajak semua menuju kebahagiaan menggapai surga. 
7. Tulisan Syubbanul Musliminhuruf latin di bawah berwarna putih menunjukkan bahwa kita ingin mengajak kepada kesucian dan kebaikan. Tulisan fontnya semi latin dan arab menunjukkan agama dan budaya tidak bisa dipisahkan, bersatu padu hingga kita menjadi Indonesia.

8. Warna hitam dibawah bermakna bahwa kami adalah majelis yang kompak, kokoh, kuat. Mampu mewarnai dan bermanfaat untuk umat. (Wawancara dengan Ridwan, anggota Tim Desainer Syubbanul Muslimin, $16 / 06 / 2019$ )

\subsection{Strategi "Image-Banding" Majelis Syubbanul Muslimin}

Yang unik dari Majelis Syubbanul Muslimin adalah menggunakan strategi branding seperti yang dilakukan oleh majelis-majelis shalawat pada umumnya, sebutlah misalnya Syekhermania. Dalam sebuah risetnya tentang majelis taklim dan majelis shalawat, Syamsul Rijal (2020) menjelaskan bahwa majelis taklim dan shalawat di Indonesia menjadi salah satu pasar keagamaan (religious market) dengan memanfaatkan berbagai media baru (new media) yang tersedia. Sebenarnya, hal itu juga berlaku pada Majelis Syubbanul Muslimin yang menggunakan musikalitas (musicality) untuk merepresentasikan branding Rasulullah lewat dekorasi panggung, buku, hingga performa.

Berdasarkan serangkaian observasi dan wawancara dengan narasumber, berikut ini akan disajikan beberapa data terkait dengan bagaimana Majelis Syubbanul Muslimin menjalankan strategi branding tersebut untuk membumikan shalawat.

\section{a. Dekorasi Panggung, Lagu Shalawat, dan Publikasi Buku}

Untuk menjaga penampilan Syubbanul Muslimin agar tetap impresif, Tim Dekorasi turut berkontribusi dalam penataan desain panggung agar terlihat memukau. Gemerlapnya desain panggung Syubbanul Musliminsengaja dipoles serapi mungkin agar latar belakang panggung terlihat menarik, sehingga mampu menyedot perhatian jamaah untuk menghadiri kegiatan shalawatan Syubbanul Muslimindan mereka merasa nyaman saat duduk di majelis. Seperti yang dipaparkan Samleo koordinator Tim Dekorasi Syubbanul Muslimin.
"Keinginan membantu Sang Kyai. Pernyataan itu kira-kira yang menggambarkan perasaan kami dalam menghiasi tim dekorasi Syubbanul Muslimin dengan berbagai keindahan, mulai dari penataan lighting, bunga indah menawan, hinggadesain background panggung yang bervariasi. Setiap penampilan Syubbanul Musliminterlihat memukau dengan konsep yang dibuatnya. Kami senang membantu Gus Hafidzul Hakim Nur bahkan dengan sukarela dan penuh kecintaan, hingga kami tak memperdulikan kapan waktunya istirahat, karena bagi kami siang ataupun malam adalah sama". (Wawancara dengan Samleo, anggota Tim Dekorasi Syubbanul Muslimin, 12/11/2019)

Kegiatan melaksanakan berdakwah di masyarakat tentu tidak cukup dengan memberikan pemahaman keagamaan saja, mengingat makna dakwah sendiri cukup luas sehingga membutuhkan revolusi dalam menjalankan amar makruf dan nahi munkar tersebut. Jika hal demikian tidak dilakukan, maka akan dikhawatirkan kemasan dakwah akan berjalan stagnan. Misalkan shalawat pada tempo dulu yang hanya digemari oleh orang-orang sepuh, sedangkan anak-anak muda jarang menyukai shalawat. Berangkat dari fenomena di atas, timbullah ide dari Gus Hafidz untuk mengkemas shalawat dengan mengubah lirik dari lagu-lagu yang popular di sosial media.

Misalnya lagu Jaran Goyang diadaptasi liriknya, diisi dengan bacaan shalawat. Ini adalah salah satu cara Syubbanul Musliminmenjadikan bacaan shalawat, agar lebih familiar utamanya dengan kaum milenial. Dalam istilah jurnalistik, upaya yang dilakukan oleh Syubbanul Musliminitu bertujuan agar bacaan shalawat yang ditampilkan, memiliki proximity (kedekatan) dengan jamaah. Begitu jamaah sudah berhasil didekati, dan jamaah sudah tertarik dengan Syubbanul Muslimin, tahapan selanjutnya adalah menanamkan spritualitas pada diri mereka. 
Seperti apa yang diungkap Gus Hafidz bahwa:

"Ciri khas Syubban adalah mengikuti tren yang berkembang saat ini termasuk mengadaptasi lagu trending di media sosial ke dalam bentuk lagu shalawat. Misalkan lagu Aisyah Istri Rasulullah diadaptasi liriknya menjadi lagu shalawat. Hal ini dilakukan agar dakwah Syubbanul Musliminlebih dekat dan menyesuaikan dengan zaman saat ini serta lebih mudah diterima di masyarakat". Saat saya berada di Syubbanul Muslimin bisa membuat saya lebih baik, membuat saya lebih dewasa, bisa menjadi petunjuk bagi saya. Di saat saya gundah dan gelisah ada Abuya Hafidz Hakim yang selalu memberikan wawasan dan nasehat. Saya berpesan kepada Syubban LoversNusantara semua untuk lebih mencintai guru dan washilah menuju Allah dan rasulullah. Syubban adalah majelis yang bagus bagi para pemuda untuk mengenal Allah dan rasulullah. Insyaallah semuanya barokah, istiqomah tanpa batas, semua karena cinta". (Wawancara dengan Gus Hafidz, Ketua Majelis Syubbanul Muslimin, 20/11/2019)

Publikasi penampilan Syubbanul Muslimin di sosial media terus diperkuat bahkan tidak hanya berhenti di situ, tim Syubban telah melaunching buku dengan judul Majelis Syubbanul Muslimin, Menebar Dakwah dengan Cinta. Dalam buku tersebut mengisahkanperjalanan dakwah Syubbanul Muslimin, perjuangan, sejarah berdirinya Majelis Syubbanul Muslimin hingga kepopuleran sampai saat ini. Seperti yang diceritakan oleh Moh. Nasirul Haq selaku penulis buku mengatakan :

"Perlu kiranya sepak terjang Majelis Syubbanul Muslimindinarasikan dalam bentuk buku. Hal itu dilakukan agar perjuangan yang pernah ditunaikan dulu dapat dikisahkan dalam bentuk goresan pena sehingga dapat dibaca oleh semua orang termasuk penggemar Syubbanul Musliminyang saat ini masih setia melantukan shalawatnya. Di sisi lain, menulis bagi saya merupakan hobi dan khidmah, termasuk konsisten dalam menebarkan dakwahnya melalui tulisan-tulisan. Saya memulai karya dengan menulis buku saat masih mengenyam bangku kuliah di Universitas Imam Syafi"I Hadramaut Yaman. Tercatat sudah 7 buku pernah ditulis, di antaranya Back to Root "Kembali ke Akar. Ditulis dan dicetak saat masih aktif menjadi mahasiwa, Metode Bahasa Arab, Ibarot Qoshiroh Zaman Now, Akidati/Akidahku,

PesantrenDarussalam Sumbersari, 70 tahun mempertahankan tradisi memaksimalkan eksistensi dan terakhir Majelis Syubbanul Muslimin, Menebar Dakwah Dengan Cinta. Kami selaku tim multimedia juga mendesain jadwal pementasan Syubbanul Musliminselama kurun waktu sebulan ke depan. Hal itu pada nantinya bakal memudahkan jamaah dalam mengakses info Syubbanul Muslimin. Selain itu, kami mendesain quote, ataupun kata-kata Islami dari Gus Hafidz yang hal ini akan menambah kecintaan jamaah terhadap lagu shalawat. Polesan desainsederhana terus dilakukan untuk memberikan kemudahan bagi jamaah dalam mengakses info Syubbanul Muslimin, sehingga pada nantinya mereka setia". (Wawancara dengan Moh. Nasirul Haq, penulis buku Syubbanul Muslimin, Menebar Dakwah dengan Cinta, 12/12/2019)

Kepopuleran Majelis Syubbanul Musliminturut dirasakan oleh Kurniawan Muhammad selaku Direktur Jawa Pos Radar Malang. Ia menyebut shalawat Syubbanul Musliminsebagai shalawat spritualitas, di mana setelah jamaah berhasil didekati maka tahap selanjutnya menanamkan spritualitas agar menyukai shalawat. Biasanya spritualitas ini baru dirasakan oleh seseorang yang sudah beranjak tua atau baru dirasakan pentingnya ketika seseorang memasuki 
tahapan baru dalam kehidupannya. Misalnya memasuki dunia kerja, atau memasuki kehidupan rumah tangga. Sementara di usia muda pada umumnya masih dalam usia belajar terkesan sulit menanamkan spritualitas pada diri mereka.

\begin{abstract}
"Saya melihat, Syubbanul Muslimin bisa menjadi media untuk menanamkan spritualitas pada generasi milenial melalui bacaan shalawat, dan rupanya metode yang dipergunakan Syubbanul Muslimin dalam membangun awareness agar generasi milenial menyukai shalawat cukup mengena. Ini terbukti, penampilan Syubbanul Muslimin di sejumlah daerah hampir selalu dipadati jamaah yang kebanyakan kaum milenial. Penampilan Syubbanul Musliminyang diunggahdi media sosial, khususnya di youtube, cukup banyak mendapat respon. Kabarnya, dari channel Youtube, Syubbanul Muslimin mendapat ratarata pendapatan 30 juta per bulan. Ini berkat banyaknya yang melihat dan mengunduh penampilan Syubbanul Muslimin melalui channelnya." (Wawancara dengan Kurniawan Muhammad, Direkur Jawa Pos Radar Malang, 20/06/2019)
\end{abstract}

Pernyataan Kurniawan Muhammad di atas memperlihatkan bahwa Syubbanul Muslimin juga menjalankan strategi branding melalui pemanfaatan media internet, seperti Youtube, dan media sosial lain (Whatsapp, Facebook, Instagram). Per hari ini saja (15 November 2020), jumlah pelanggan channel Youtube Syubbanul Muslimin (SyubbanTV) mencapai 2,31 juta Subcriber, sementara jumlah pengikut Instagram (syubbanulmuslimin.id) mencapai 24,7 ribu Followers. Jumlah ini belum termasuk data di Facebook, website, dan beberap akun official lainnya. Kondisi ini jelas menunjukkan bahwa majelis ini memang menyasar generasi milenial dan masyarakat kelas menengah Muslim dalam mempromosikan kegiatan dan produkproduknya.

\section{b. Strategi "Performasi" Rasulullah}

Selain mendekorasi panggung, memodifikasi lagu, dan mempublikasikan buku, Majelis Syubbanul Muslimin juga menjalankan strategi image-branding dengan menampilkan performasi Rasulullah, semacam melakukan indoktrinasi secara kultural. Setidaknya, terdapat tiga tahap performasi yang dijalankan oleh Majelis Syubbanul Muslimin dalam menjalankan dakwahnya di masyarakat.

1) Mensyiarkan majelis kepada semua orang bahwa Syubbanul Muslimin adalah majelis yang asyik mengajak anak muda shalawatan dan mengingat Allah. Itulah mengapa di awal-awal, Syubban sering konvoi, bakti sosial, dan turun dalam kegiatan kemasyarakatan.

2) Membuat betah atau melembutkan hati. Membuat jamaah yang hadir di majelis betah dengan apa yang ada dalam majelis dengan shalawat yang meriah dan suasanayang meneduhkan. Pada gilirannya mereka akan rindu untuk datang lagi ke Syubbanul Muslimin. Oleh karena itu, Gus Hafidz di awal-awal tidak mengusir anak Syubban sering membuat onar dalam kegiatan shalawat Syubbanul Muslimin, justru mereka diayomi.

3) Mengukuhkan atau doktrin. Metode terakhir ini merupakan, setelah jamaah betah di dalam majelis mereka kemudian diajarkan ilmu agama, atau tanpa kita ajarkan mereka sendiri akan meminta untuk diajarkan ilmu agama. Dengan 3 tahapan ini maka sampailah inti dari dakwah. (Haq, 2019)

"Salah satu syarat yang paling utama menurut saya adalah kita menjadi mereka, tapi kita tidak terpengaruh dengan mereka. Jadi kita perlu memahami arus mereka. Istilahnya saya mengikuti arus tapi saya tidak terbawa arus. Mungkin ketika kita di majelis, saya pakai imamah dan jubbah. Bukan untuk sombong, akan tetapi saya ingin memahamkan bahwa ini majelisnya Rasulullah dan kita perlu memberi penghormatan terbaik 
dengan berpenampilan rapi dan santun. Kalau saya bareng sama mereka, kita duduk bareng, sharing dan bercanda. Bahkan rapat majelis sering kita selenggarakan di café, berpakaian rapi seperti mereka. Jadi intinya kita perlu menyelam menjadi mereka dan akan tetapi tujuannya mereka juga harus menjadi kita. Maksudnya untuk menarik mereka ke jalan yang baik. Syubban juga bisa besar dan kompak seperti sekarang ini di antaranya karena kita sering saling bersilaturrahmi. Mereka jugalah yang menjadi keluarga saya, di manapun mereka berada saya sering mendatangi rumah mereka. Istilah kita jemput bola agar bisa bermain bola." (Wawancara dengan Gus Hafidz, 25/06/2019)

Pernyataan di atas memperlihatkan bahwa 'performasi Rasulullah' ini ditunjukkan oleh Gus Hafidz dengan jubah dan imamah. Penggunaan imamah dan jubah bukan sekadar bentuk penghormatan, tapi juga penampilan suatu citra (image) tentang kesucian Rasulullah di hadapan para jamaah. Hal ini tentu memberikan efek psikologis tertentu kepada para jamaah yang sejak awal memang mendambakan kehadiran Rasulullah di dalam majelis ini.

Pernyataan Gus Hafidz di atas juga memperlihatkan upaya beliau untuk meneladani perilaku Rasulullah dalam berdakwah dengan cara bernampilan rapi dan santun, mendatangi rumah jamaah, hingga musyawarah, perilaku-perilaku yang khas dilakukan oleh Rasulullah dan telah menjadi populer dalam sejarah peradaban Islam. Pernyataan itu sekaligus untuk memperlihatkan bahwa Gus Hafidz melalui Syubbanul Muslimin memiliki suatu kriteria yang pantas untuk dinisbatkan, diasosiasikan dengan perilaku Rasulullah.

Dengan demikian, performasi Rasulullah yang dimaksud di sini adalah menampilkan citra Rasul dalam ruang publik, dan pernyataan Gus Hafidz di atas telah menunjukkan hal tersebut sebagai suatu deklarasi simbolik tentang pentingnya mengikuti ajarak Nabi melalui Majelis Syubbanul Muslimin. Oleh karena itulah, performasi itu dilakukan dengan terus menerus memberikan pengetahuan dan promosi psikologis kepada para jamaahnya melalui citra nabawi (prophetic image) di berbagai ruang yang bisa diakses secara langsung oleh jamaah, utamanya dari kalangan remaja, pemuda, atau umat Muslim kelas menengah.

\subsection{Strategi "Marketing" Syubbanul Muslimin}

Majelis Syubbanul Muslimin juga menggunakan teknologi komunikasi baru sebagai instrumen untuk mempromosikan majelis dan menyebarkan pesan kepada para jamaahnya. Penggunaan media baru itu, misalnya melalui Internet, berupa jadwal, program, dokumentasi acara, lagu-lagu, hingga link Youtube, dan sosial media juga menjadi upaya majelis untuk memasarkan diri dan tentu saja mengajak para jamaah untuk terlibat dalam mendukung dan menjadi followers majelis tersebut melalui donasi tak langsung.

Berikut ini akan dijelaskan secara singkat beberapa strategi marketing yang dijalankan oleh Majelis Syubbanul Muslimin kepada para jamaahnya melalui pemanfaatan teknologi mutakhir untuk memastikan kegiatan majelis tersebut tetap berjalan.

\section{a. Publikasi Syubbanul Muslimin ke Sosial Media}

Keberhasilan Majelis Syubbanul Muslimindalam berdakwah di sosial media tidak terlepas dari sentuhan tim mutlimedia yang terus konsistenmempublikasikan karya-karya lagu shalawat personel Syubbanul Musliminke akun media syubban baik melalui channel Facebook, Instagram, ataupun Youtube. Seiring dengan komitmen dan istiqomahnya tim multimedia sebagai crew yang bertugas mengunggah penampilan Syubbanul Muslimindengan lagu shalawatnya yang khas. Lagu tersebut menyesuaikan tren saat ini sehingga lebih dekat dan diterima oleh masyarakat luas utamanya kalangan milenial yang perlahan menggandrungi shalawatan, bahkan tidak jarang dari mereka rela berangkat jauh-jauh untuk menghadiri Majelis Syubbanul Muslimin. Keberadaan sosial media betul-betul dimanfaatkan secara positif oleh tim kreatif media syubban sebagai sarana berdakwah saat ini. 

$\begin{array}{cc}\text { "Karena Syubban dakwah angguy } \\ \text { media } & \text { sosial }\end{array}$ mamude"aginakses dakwah saengge lebih cepet eterema e masyarakat. Napapole jeman mangken ampon canggih dengan kabedeen komputer, hp, internet bik selaenna. Saengge sareng tim multimedia nika lagu-lagu shalawat syubban e upload e internet cong. (Karena Syubbanul Muslimin menggunakan media sosial agar mempermudah dakwah, sehingga lebih cepat diterima di masyarakat. Terlebih saat ini zaman semakin canggih dengan keberadaan komputer, handphone, internet dan lain sebagainya. Berkat tim multimedia tersebut, lagu-lagu Syubbanul Muslimin diunggah ke internet). (Wawancara dengan Babun Ni'am, anggota Tim Kreatif Media Syubbanul Muslim, 25/07/2019)

Untuk mendukung penggunaan media sosial, majelis shalawat Syubbanul Muslimin memiliki tim multimedia tersendiri. Di mana tim ini bergerak di bidang media baik peremakan audio, pengambilan gambar, pembuatan video klip, mendesain, dan konten-konten lainnya yang dapat dijadikan bahan untuk memperkenalkan Syubbanul Musliminpada masyarakat luas melalui media sosial. Di antara media sosial yang digunakan adalah Youtube, Instagram, Facebook, media cetak, fashion, dan lain sebagainya. Media digunakan untuk mempermudah masyarakat mengenal Syubbanul Muslimin. Dengan begitu, dakwah melalui lagu-lagu Islami mudah diterima di masyarakat.

Untuk mendukung pengembangan sosial media, crew multimedia Syubbanul Musliminmem buat kata motivasi, katakata Islami, ataupun dalam bentuk ceramah dari Gus Hafidzul Hakim Noer. Pembuatan nasehat-nasehat Islami yang diinisiasi oleh Gus Hafidz sebagai bentuk mengingatkan pemuda untuk kembali pada jalan yang benar.

Beberapa contoh nasehat Islami dari Gus Hafidz ,yakni "Shalatmu cerminan hidupmu, Barangsiapa terbiasa mengakhirkan shalat baik laki-laki maupun perempuan. Maka bersiaplah ia terlambat dalam segala urusan kehidupannya (nikah, pekerjaan, keturunan, kesehatan, kemapanan, petunjuk)". (22 Januari 2018). "Ketika kamu mampu menyayangi seseorang tanpa sebab dan tanpa syarat. Maka, kamu akan mulai memahami kasih sayang Allah kepadamu tanpa syarat" (21 Januari 2019). "Dunia terlihat indah walau menipu, dan semua orang yang tahu pasti akan meninggalkannya. Kematian terlihat buruk namun nyata dan orang mengabaikannya". (12 Januari 2018). "Perkumpulan yang baik akan menjadikan engkau orang yang baik, meskipun engkau adalah orang yang rusak atau buruk. Sedangkan perkumpulan yang buruk akan menjadikan engkau orang yang buruk meskipun engkau adalah orang yang baik." (19 Januari 2018).

"Di Instagram saya dan buku yang pernah ditulis oleh teman-teman terdapat kata-kata motivasi, katakata mutiara, nasehat-nasehat Islami, dokumentasi kegiatan Syubban, informasi jadwal manggung Syubbanul Muslimin. Motivasi Islami tersebut penting dilakukan mengingat era saat ini rentan terpengaruh oleh imbas globalisasi utamanya kalangan pemuda yang aktif menggunakan sosial media. Pengaruh teknologi informasi atau sinetron yang mempertontonkan perilaku kejelekan cenderung ditiru oleh masyarakat utamanya anak muda. Misalnya adegan kekerasan, balap motor, minuman keras dan lain sebagainya. Keberadaan Majelis Syubbanul Musliminsebagai lembaga dakwah diharapkan dapat membendung segala bentuk penyimpangan yang ada, ditambah dengan nasehat-nasehat Islami. Pada gilirannya, perlahan jamaah akan mendekatkan diri pada Allah dan rasulullah". (Wawancara dengan Gus Hafidz, Ketua Majelis Syubbanul Muslimin, 26/07/2019) 
Seiring konsistennya crew multimedia Syubbanul Muslimin mengunggah penampilannya ke channel Youtube, mereka memperoleh penghargaan berupa emas platinum dan hingga saat ini disimpan rapi di kantor pusat Syubbanul Muslimin. Seperti yang pernah diceritakan H. Zain selaku Koordinator Tim Multimedia Syubbanul Muslimin.

"Penghargaan ini kami peroleh bukan tanpa perjuangan dan bagi kami ini merupakan penghargaan bersejarah yang pernah kami raih selama keikutsertaan mengurus syubban. Awal mulanya hanya menggunakan handphone biasa untuk merekam kegiatan syubban. Lambat laun dibelikan laptop oleh Gus Hafidz untuk mengembangkan media syubban. Akhirnya hingga jadi seperti ini dan kami terus istiqomah menyebarkan dakwah di masyarakat tidak hanya di dunia nyata, akan tetapi di dunia maya. Tujuannya agar masyarakat juga bisa menikmati lagu-lagu Syubbanul Muslimin. Penghargaan berupa emas batangan dan platinum tersebut saat ini disimpan di kantor syubban dan tertata rapi." (Wawancara dengan $\mathrm{H}$. Zain, Koordinator Tim Multimedia Syubbanul Muslimin, 25/07/2019)

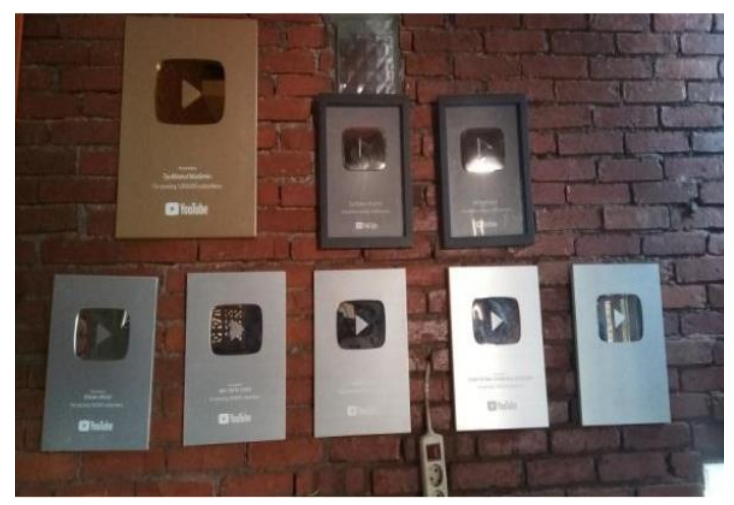

Gambar 2. Deretan Penghargaan Silver Play Button dari Youtube

Semenjak Syubbanul Muslimin memperoleh penghargaan berupa emas batangan dan uang pembinaan dari Youtube, hal itu turut mendongkrak pada meningkatnya penggemar Majelis Syubbanul Musliminbaik di dunia virtual ataupun media sosial. Syubband
Loverssebutan bagi penggemar Syubbanul Muslimindi nusantara. Setiap penampilan yang diunggah ke media sosial tersebut hampir menempati urutan teratas pada tangga lagu di youtube. Ahmad Syaifullah selaku anggota multimedia memaparkan bahwa setiap kali penampilan Syubban diunggah ke media sosial selalu ditonton banyak orang.

"Setiap kali penampilan Syubbanul Muslimin diunggah ke media sosial misalnya instagram ataupun youtube, selalu ditonton ratusan ribu pengguna youtube. Hal ini sekaligus menjadi keberhasilan syubban dalam melakukan dakwah melalui media sosial." (Wawancara Ahmad Syaifullah, anggota Tim Multimedia Syubbanul Muslimin, 26/07/2019)

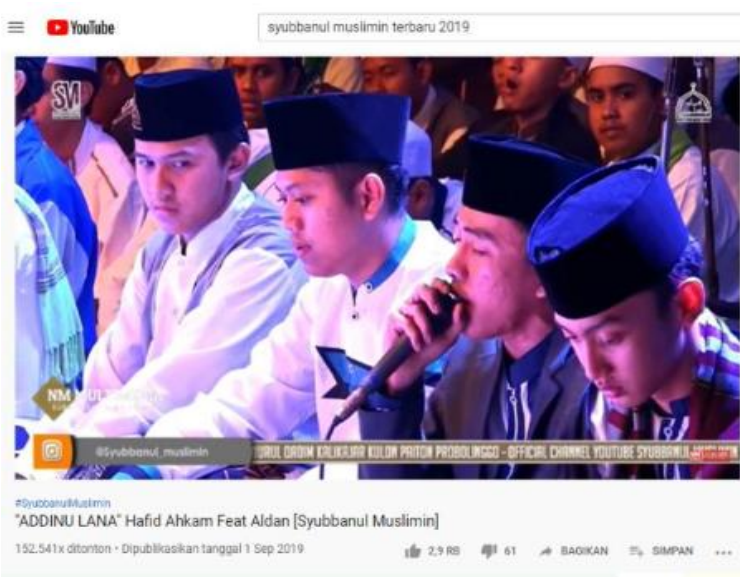

Gambar 3. Penampilan Personel Syubbanul Muslimin

Peran media Syubbanul Muslimin dalam berdakwah dapat dikatakan berjalan cukup efektif. Hal tersebut dapat dilihat dari bagaimana jumlah followers di Instagram misalnya semakin meningkat, bahkan saat ini telah mencapai 964 ribu follower. Jumlah subscriber di Youtube telah menyentuh angka 1,74 juta dengan 489 unggahan videonya.

Jumlah jamaah yang mengikuti kegiatan shalawat Syubbanul Muslimindalam tiap tahunnya selalu mengalami peningkatan di mana didominasi oleh kalangan pemuda yang sangat antusias mengikuti acara shalawatan tersebut.Seperti yang dikatakan GusHafidz bahwa jumlah jamaah dalam setiap tahunnya semakin gemar 
bershalawat. Hal tersebut tidak terlepas dari harapan pihak Syubban yang selalu membumikan shalawat di Indonesia dan dunia.

"Tahun 2018 saja, jumlah jamaah yang menghadiri kegiatan Syubbanul Muslimin menyentuh angka 10 hingga 13 ribu jamaah. Sementara di tahun 2019 nya, telah mencapai angka 15 ribu jamaah baik yang berasal dari lokal ataupun luar kota. Jamaah yang hadir di majelis adalah didasari rasa cinta pada Allah dan Rasulullah. Syubban sebagai perantara menuju rasulullah, Syubban membimbing pemuda untuk dekat dengan Rasulullah SAW. Maka jangan heran jika perantara bagi para pecinta adalah hal yang sama dengan tujuan utamanya." (Wawancara dengan Gus Hafidz, Ketua Majelis Syubbanul Muslimin, 29/07/2019)

\section{b. Membangun Jaringan Syubban Lovers Nusantara}

Ketenaran nama Syubbanul Muslimindi sejumlah daerah bahkan terdengar hingga penjuru tanah air karena tidak terlepas dari peran Syubban Lovers Nusantara (SLN) sebagai grup untuk mewadahi jamaah syubban. Terbentuknya grup ini bermula dari inisiatif salah satu anggota syubban bernama Moh. Ainur Huda yang saat itu mengajak jamaah chatting di DM Instagram. Melihat respon jamaah cukup antusias sehingga timbul di pikirannya untuk mewadahi mereka melalui Syubban LoversNusantara. Akhirnya grup ini diresmikan oleh Gus Hafidz pada tanggal 26 Maret 2018 lalu.

Grup ini sengaja dibuat untuk memudahkan informasi terkait Majelis Syubbanul Muslimin. Selain itu, melihat maraknya grup-grup baik di Facebook, Instagram, dan di media sosial lainnya yang mengatasnamakan pecinta Syubbanul Muslimin. Dikhawatirkan jika ini tidak diwadahi secara resmi akan muncul info-info hoax, pemungutan dana illegal, atau berbagai penipuan berkedok Syubbanul Muslimin. Sementara itu, Syubban Lovers Nusatara karena sudah ngefans pasti akan melakukan apa saja untuk idolanya. Oleh karena itu, tim SLN merasa perlu untuk membuat sebuah grup resmi yang bisa merangkul pecinta syubban di sejumlah pelosok daerah inilah yang melatarbelakangi penambahan istilah Nusantara di belakang kata Syubban Lovers Nusantara, tutur Moh. Ainur Huda selaku Koordinator Pusat Majelis Syubbanul Muslimin.

"Di antara kota yang pertama kali memiliki koordinator yaitu Mojokerto, Tegal, Pekalongan, Serang, Jombang, Malang, Sragen dan Jember." (Wawancara dengan Moh. Ainur Huda, Koordinator Pusat Syubbanul Muslimin, 15/07/2019)

Setelah Syubban Lovers Nusantara terbentuk, Ainur Huda memberikan pengarahan terkait agenda Syubbanul Musliminselama ke depannya agar tetap konsisten. Ainur Huda senang dengan adanya korda ini karena lebih mudah untuk menyatukan Syubban Loversdi sejumlah daerah di Indonesia, bahkan saat ini sudah terbentuk 27 korda di berbagai kota di Indonesia, misalnya Bojonegoro, Gresik, Kota Probolinggo, Situbondo, Bondowoso, Tegal, Jakarta, Bandung, Balikpapan, dan sejumlah kota di Indonesia yang turut bergabung membentuk Syubban Lovers Nusantara.. Dengan adanya korda-korda inilah Syubban Lovers Nusantara semakin tertatadengan baik. Harapannya, dengan dibentuknya korda ini Syubban Loversdapat lebih tertata dengan baik ke depannya.Pada gilirannya, akan memupuk jamaah untuk menyukai shalawat.

"Syubban Lovers Nusantara atau yang disingkat SLN ini dibentuk karena banyaknya. Di dalam grup itu mereka bisa berbagi info terkait syubban akan tampil di mana, mendapatkan video, quote ceramah dari Gus Hafidz Hafidzul Hakim, atau memberikan saran bagi sesama yang ingin hijrah untuk menuju lebih baik lagi. Intinya bagaimana menanamkan kecintaan kepada ulama. Alhamdulillah banyak Syubban Lovers yang penampilannya 
Islami dan obrolannya juga Islami. Hal ini karena pengaruh temanteman yang baik merekapun ikut baik. Syubban Lovers memiliki visi dan misi yang diproklamirkan oleh Gus Hafidzul Hakim selaku Shohibul Majelis Syubbanul Muslimin yang isinya sebagai berikut: Menjadikan shalawat sebagai tuntunan bukan tontonan, menanamkan cinta kepada Allah dan rasulullah SAW dan membumikan shalawat." (Wawancara dengan Moh. Nasirul Haq, penulis buku Majelis Syubbanul Muslimin, 18/07/2019)

Respon jamaah terhadap keberadaan Majelis Syubbanul Muslimin perlahan menjadi daya tarik terhadap jamaah untuk lebih menyukai shalawat, bahkan kehadiran syubban selalu diidam- idamkan oleh SLN di mana pun mereka berada meski harus jauh-jauh datang menghadirinya. Hal itu dilakukan tak lain ingin mengharap berkah dan barokah dari sang Guru Buya Yahya Hafidzul Hakim selaku pembina Majelis Syubbanul Muslimin. Selain itu, Syubban Lovers Nusantara juga terpukau dengan kharisma Gus Hafidz. Seperti yang pernah diceritakan oleh Maya Firdausi perwakilan Syubban Lovers dari Gresik.

"Saya yakin, semua sudah tahu bahwa Syubban Lovers tersebar seantero nusantara. Bagi Syubban Lovers sosok Gus Hafidz adalah ruh majelis ini. Jamaah SLN selalu terkesima dengan kharisma beliau, tatapan beliau yang menyejukkan hati, serta senyum beliau yang membuat hati tenang. Ia selalu kami nanti-nantikan di manapun, kapanpun jejak dakwah yang beliau lalui. Kami tak pernah mengenal jarak, waktu tenaga, dan materi. Semua kami korbankan untuk mendapatkan berkah guru kami. Guru yang senantiasa tak kenal lelah mendampingi syubban loversbeserta jamaah melalui tausiyah dan ilmu yang diajarkan pada kami. Kami belajar pada Gus Hafidz tentang makna cinta yang tak pernah tahu ujungnya, dan istiqomah yang tiada batasnya. Guru kami SLN selalu berada di belakangmu. Mendukung setiap jengkal dakwahmu. Di manapun engkau menoleh dan engkau mendapati kami di sana. Ajaklah kami senantiasa mencintai Allah dan rasulnya seperti yang selama ini engkau ajarkan kepada kami." (Wawancara dengan Maya Firdausi, perwakilan Syubban Lovers dari Gresik, 23/07/2019)

Pernyataan Firdausi di atas memperlihatkan bahwa pemanfaatan media baru (new media) yang dilakukan oleh Majelis Syubbanul Muslimin telah berhasil bukan hanya menciptakan meningkatnya kecintaan dan popularitas Gus Hafidz dan Gus Azmi, melainkan juga mampu membangun sejenis jaringan informal yang dapat mengikat para pengikut (followers) tersebut. Syubban Lovers Nusantara (SLN) merupakan bukti bahwa Syubbanul Muslimin telah berhasil menggiring para jamaahnya untuk sukarela membentuk sebuah komunitas yang di dalamnya mereka bisa saling berdiskusi dan berbagi cerita dan kesan tentang idola mereka, serta saling berbagi informasi soal jadwal manggung dan perkumpulan-perkumpulan lainnya.

\section{Penutup}

Jelaslah di sini bahwa shalawat sebagai sebuah aktivitas "keagamaan" dan/atau "seni" maupun sebagai "ritual" telah di(re)produksi dalam praktik-praktik sosial yang spesifik yang menghubungkan antara masa lalu dengan sekarang. Berbagai upaya dilakukan agar "citra masa lalu" tetap hidup di dalam ingatan dan keseharian kita sebagai referensi dan cara untuk merespons kondisi kekinian. Shalawatan yang masih berlangsung hingga sekarang, sebagaimana tampak pada beberapa penilitian, tradisi dianggap perlu tetap "dilestarikan" atau "dipertahankan". Tradisi seolah harus bersifat luwes dan cair sehingga bisa terus menerus menzaman (Laksono, 1985: 10).

Namun, di dalam proses peluwesan ia membutuhkan agensi-agensi atau aktor-aktor dan juga konteks-konteks lain yang melingkupinya. Menurut Zamzan Fauzanafi, mengikuti pendapat Stange (2009: 67), tradisi 
sebenarnya merupakan produk kebudayaan kontemporer (2005: 21-22). Karena sebagai produk kontemporer, ia berkaitan dengan aktualitas (yang dialami dalam kesekarangan). Shalawat tetap "mengaktual", berarti mengandaikan suatu proses di mana pengaktualan ini adalah sebentuk "komodifikasi" untuk tetap bertahan dan beradaptasi dengan segala perubahan zaman.

\section{Daftar Pustaka}

Barendregt, B., \& Zanten, W. V. (2002). "Popular Music in Indonesia since 1998, in Particular Fusion, Indie, and Islamic Music on VideoCompact Discs and the Internet." Yearbook for Traditional Music, 34, 67-113.

Dicks, B. 2003. "Action, Experience, Communication: Three Methodological Paradigms for Researching Multimodal and Multisensory Settings." Qualitative Research Online. Diakses dari http://arj.sagepub.com/content/early /2013/09/10/1468794113501687, 10 Februari 2017.

Fairuz, R. (2013). "Maulid and Shalawat in Popular Culture Perspective: Study of Jamaah Ahbabul Musthofa Yogyakarta." Research Paper. Yogyakarta: Fakultas Adab dan Humaniora, UIN Sunan Kalijaga Yogyakarta.

Fauzanafi, M. Z. (2005). Reog Ponorogo: Menari di antara Dominasi dan Keragaman. Yogyakarta: Kepel Press.

Haq, M. N. (2019). Syubbanul Muslimin: Menebar Dakwah dengan Cinta. Probolinggo: Majelis Syubbanul Muslimin Press.

Hardiman, F. B. (2007). "Manusia sebagai Ada yang Mendunia: Maurice MerleauPonty tentang Tubuh dan Ruang." Filsafat Fragmentaris. Yogyakarta: Kanisius.
Hirschkind, C. (2005). "Cassette Ethics: Public Piety and Popular Media in Egypt," dalam Birgit Meyer dan Annelies Moors. Religion, Media, and the Public Sphere. Indianapolis: University of Indiana Press.

Howes, David (ed.). 1991. The Varieties of Sensory Experience: A Sourcebook in the Anthropologicy of the Senses. Toronto: University of Toronto Press.

Laksono, P. M. (1985). Tradisi dalam Struktur Masyarakat Jawa Kerajaan dan Pedesaan: Alih Ubah Berpikir Orang Jawa. Yogyakarta: Gadjah Mada University Press.

Lazuardi, E. (2009). "Menonton Perempuan Menonton." Skripsi. Yogyakarta: Jurusan Antropologi, Fakultas Ilmu Budaya, Universitas Gadjah Mada Yogyakarta.

Miles, M. B., \& Huberman, M. A. (1984). Qualitative Data AnalysisL A Sourcebook of New Methods. London: Sage Publications.

Muzakki, A. (2008). "Islam as a Symbolic Commodity: Transmitting and Consuming Islam through Public Sermons in Indonesia". In P. Kitiarsa (ed.), Religious Commodifications in Asia: Marketing God (pp. 205-219). London and New York: Routledge.

Rosyid, N. (2008). "Pembentukan Hasrat Bershalawat Bersama Habib dalam Konteks Kapitalisme Lanjut di Indonesia." Skripsi. Yogyakarta: Jurusan Antropologi, Fak. Ilmu Budaya, Universitas Gadjah Mada Yogyakarta.

Stange, P. (2009). Politik Perhatian: Rasa dan Kebudayaan Jawa. Yogyakarta: LKiS.

Whitehead, T. L. (2004). "What is Ethnography? Methodological, Ontological, and Epistemological Attributes." Cultural Ecology \& Health and Change.Maryland: University of Maryland, 2-24. 
Woodward, M. et. al. (2012). "Ordering What is Right, Forbidding What is Wrong: Two faces of Hadhrami Dakwah in Contemporary Indonesia". Review of Indonesian and Malaysian Affairs, 46(2), 105-146. 